\title{
Exploiting supporting poles to increase road traffic noise shielding of tree belts
}

\section{T. Van Renterghem}

\section{Summary}

A tree belt bordering a road can be a useful and environmentally friendly noise abatement measure when specific guidelines are followed. However, biological limitations regarding biomass density largely limit their shielding efficiency. Especially in case of recently planted belts with juvenile and thus thin trunks, acoustical efficiencies are small. The current study is a further elaboration on a previously performed large set of full-wave numerical calculations of tree belt planting schemes, where the effect of the presence of supporting poles is numerically investigated. It is shown that such poles can be used to give a juvenile non-deep tree belt a reasonable noise abatement, and that specific configurations of supporting poles in between the trees can further optimize its shielding. Making such poles absorbing could strongly increase road traffic noise abatement.

\section{PACS}

43.20.Fn, 43.28.En, 43.50.Gf, 43.28.Js 


\section{Introduction}

Tree belts bordering a road can be considered as an environmentally friendly and economically viable noise abatement solution, having an estimated benefit-cost ratio easily exceeding two [1]. When dealing with road traffic noise applications, the forest floor and the trunks exhibit the main acoustical effects [2][3]. Downward scattering by tree crowns can be considered as a negative effect of a tree belt when source and receiver are located below the canopy layer [4][5], but to a limited extent [6] due to its relevance at high frequencies ( $>2 \mathrm{kHz}$ ) only [7][8]. A tree belt reduces sound during transmission, making its efficiency distance-independent while the soil effect is fully preserved (and most often enhanced [9]). In contrast, a noise wall leads to a reduced ground effect [10] and its efficiency is rapidly lost with increasing source-receiver separation [11].

In order to make a tree belt an efficient noise reducing measure, specific planting schemes should be chosen as was previously shown by analyzing a database consisting of a large number of full-wave numerical calculations of sound propagation through tree belts [3]. Although the stem cover fraction (i.e. the fraction of the ground area taken by the tree trunk cross-sections, in plan view) was identified as the main driver of the acoustical shielding, specific planting schemes were shown to strongly deviate from this basic behavior and thus offer possibilities to increase the shielding (at the same biomass density) [3]. Tree belt depth (normal to the road) and width (along the road) were shown to be important as well [3]. In contrast, trunk height [2] and receiver distance relative to the belt (when looking at insertion losses) [3] were of limited importance. Introducing some randomness in trunk positioning or trunk diameter increases shielding [2][3].

Theoretically, higher efficiencies could be attained by further augmenting the trunk basal area, however, this conflicts with biological limits regarding access to light, nutrients and water for the trees. Some interesting approaches have been identified [3] to relax the need for high biomass density, without significantly affecting noise shielding. Rectangular planting schemes, where the tree spacing orthogonal to the road can be increased, omitting full rows of trees along the road length axis, and thinning inside the belt are examples of such measures [3].

Although deliberately adding artificial elements in between the trees has been suggested to increase the shielding of a belt in Ref. [1], the current work is novel by considering common cylindrical wooden supporting poles as a practical solution. Such poles are important for juvenile trees to ensure straight growth even under wind load. At the same time, poles increase the number of scattering obstacles and could therefore add to the shielding of the belt, without biological competition with the trees. It is numerically studied if considering specific pole configurations makes sense, given the importance of tree planting schemes [3].

\section{Calculation methodology}

The calculation methodology has been presented before [3], and is only summarized here. In brief, the $3 \mathrm{D}$ sound propagation environment is simplified to modeling propagation in two orthogonal planes as illustrated in Fig. 1. Full 3D calculations are not possible due to lack of sufficient computing power when 
aiming at capturing both the distances and a sufficient part of the sound frequency range in a realistic road traffic noise case.

In a first plane (plane number 1, see Fig. 1), parallel to the ground surface, scattering, diffraction and reflection by the tree trunks is calculated (in absence of ground reflections). The computationally intensive FDTD technique [12] is used here, needing a very fine spatial and temporal discretisation. In the other plane (plane number 2, see Fig. 1), the sound-soil interaction is predicted (in absence of trees) using the Green's Function Parabolic Equation (GFPE) method [13][14], which is computationally much faster, basically since stepping in the propagation direction can be performed at multiples of the wavelength. The latter technique accounts for the ground surface impedance discontinuities (from rigid ground to forest floor, and then from forest floor to grassland) when sound travels from the different road segments towards the receiver. The simulations in both propagation planes are combined by summing their sound pressure levels, relative to free field propagation, the latter e.g. justified by the full 3D calculations of sound propagation through tree belts as discussed in Ref. [2]. The (total) attenuation is then found by also accounting for the geometrical divergence. This operation is repeated for each road segment (represented by a point source in its centre) contributing to the receiver.

The major assumptions allowing this split-up in sound propagation in two orthogonal planes are the independency [15][16][2][17] of the soil effect from the multiple scattering process in such a relatively sparse environment like a tree belt, the limited importance of trunk height in road traffic noise applications [2], and the equivalence between a point source and a coherent line source when expressing results relative to free field sound propagation [18].
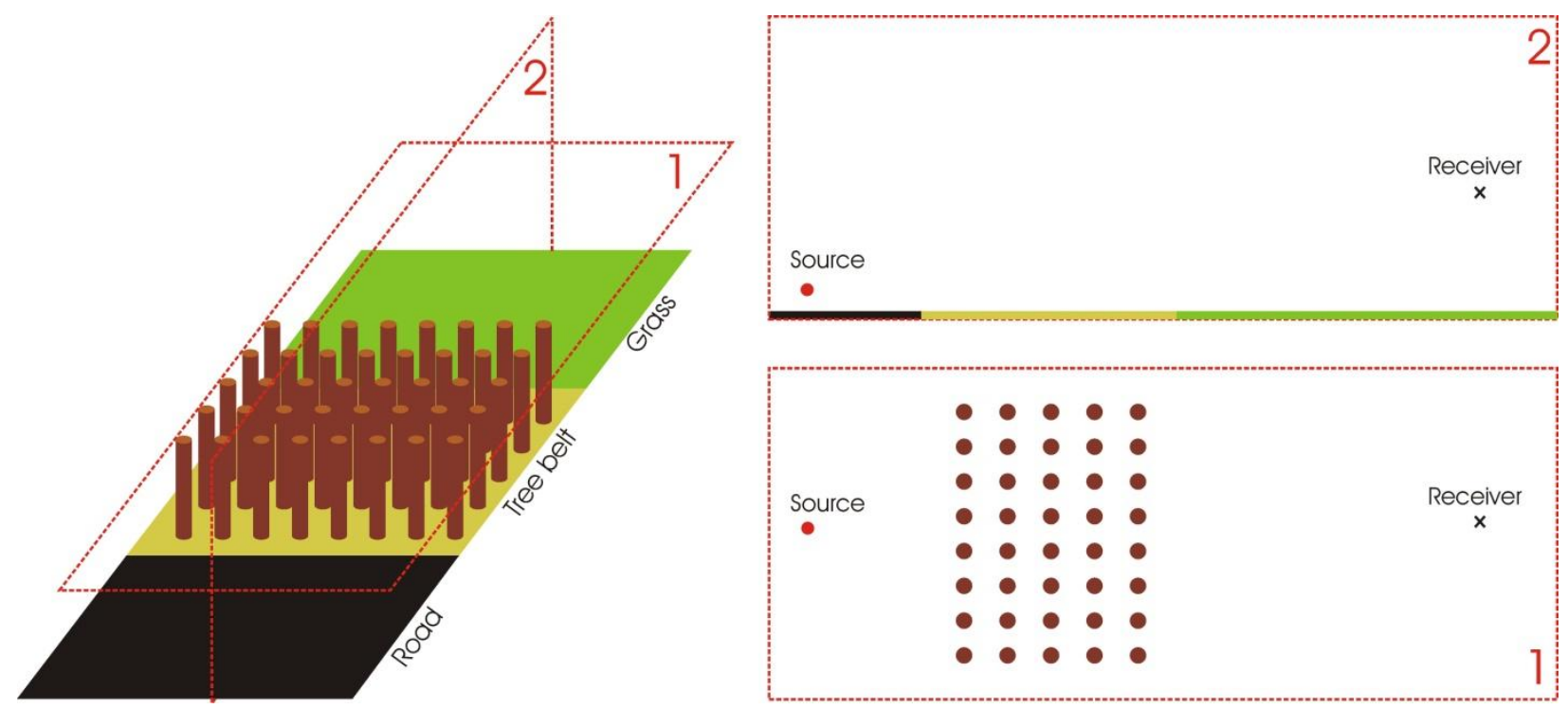

Figure 1. Illustration of splitting the 3D sound propagation environment in two orthogonal planes for a single source point.

\section{Cases}


The cases considered in this and previous work [3] consist of a 4-lane road traffic noise situation (the total width of the road is $14 \mathrm{~m}$, each lane taking $3.5 \mathrm{~m}$ ), with a receiver located at $30 \mathrm{~m}$ from the border of the road (see Fig. 2). The tree belt directly starts at the edge of the road and has a width of $15 \mathrm{~m}$. The tree belt fully covers the stretch of the road modeled, which is $100 \mathrm{~m}$. There is a uniform distribution of traffic over all lanes; light vehicles (type 1) take $85 \%$ of the fleet and they all drive at a uniform speed of $70 \mathrm{~km} / \mathrm{h}$. The same vehicle speed is assigned to the remaining 15\% heavy traffic (type 3 ). The Harmonoise/Imagine road traffic source power model [19] was used as it gives data detailed in $1 / 3$ octave bands.
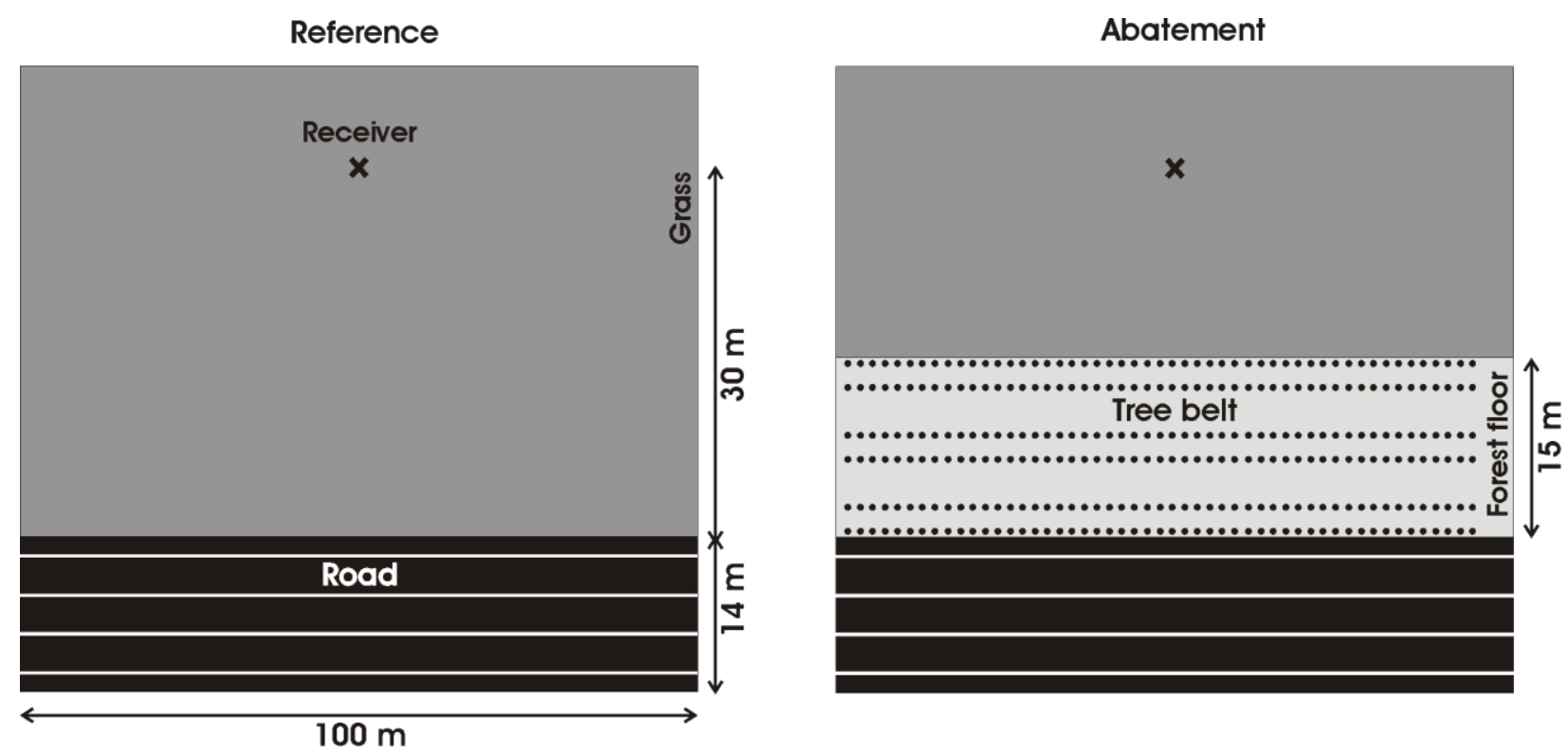

Figure 2. Plan view of the reference situation and abatement case with dimensions.

Results are represented for the hypothetical case where grassland is partly replaced by a tree belt. A homogenous and windless atmosphere is considered. The ground effect and impedance discontinuities between the rigid road surface, the forest floor and the grassland are taken into account in detail. As a simplification, it is assumed that a mature forest floor is present in all cases modeled. The modeling of the ground effect, as discussed in detail in Refs. [2] and [3], is based on validated models for which parameters were found by data fitting on a large set of outdoor measurements [20]. The road surface is modeled as fully rigid. Note that for the various tree belt cases considered, the ground effect stays the same and the GFPE simulations did not have to be repeated. This is another asset of the proposed calculation methodology separating the ground effect from the multiple scattering process.

The main focus is on non-deep tree belts to increase its applicability along roads in suburban or even urban environments. The width of the tree belts is in all cases $15 \mathrm{~m}$. Clearly, with increasing width, the efficiency might further increase in a more or less linear way as illustrated in Ref. [3]. 
Tree bark was shown to exhibit some acoustical absorption and behaves more or less frequencyindependent, as was shown by the impedance tube measurements by Reethof [21]. A real-valued and constant time-domain impedance boundary condition is therefore applied the outer surfaces of the cylinders representing the trunks in the numerical model. Although some species can have higher bark absorption, a rather conservative energetic absorption coefficient of 0.075 is used (at normal incidence), corresponding to an impedance, relative to the one of air, of $Z=51$ (further indicated as "normalized impedance"; for more details, see Ref. [3]). Unless otherwise indicated, the absorption properties of the supporting poles are modeled in the same way as those of the tree trunks.

Two tree belt configurations have been considered from the many planting schemes numerically evaluated before [3]. In a first setup, a square tree organization with a spacing of $2 \mathrm{~m}$ on $2 \mathrm{~m}$ has been considered for uniform tree diameters of $22 \mathrm{~cm}$. This corresponds to a tree trunk basal area of $1 \%$ which should be easily achievable with any kind of species. In a second setup, a rectangular grid with a spacing of $1 \mathrm{~m}$ parallel to the road, and $2 \mathrm{~m}$ orthogonal to the road, has been selected. Each third row has been omitted, which was shown before not to strongly deteriorate the road traffic noise shielding of the belt. Uniform tree diameters of $22 \mathrm{~cm}$ were considered as well here, leading to an average trunk basal area of $1.5 \%$, for which dedicated maintenance (like e.g. pollarding) or selecting specific species (like e.g. willows) might be needed. The local dense configuration in the paired rows here is relaxed by the larger space of $4 \mathrm{~m}$ (orthogonal to the road) in between the grouped rows. Randomness is not included, neither in trunk spacing nor diameter. For both planting schemes, various pole configurations were studied as depicted in Fig. 3.

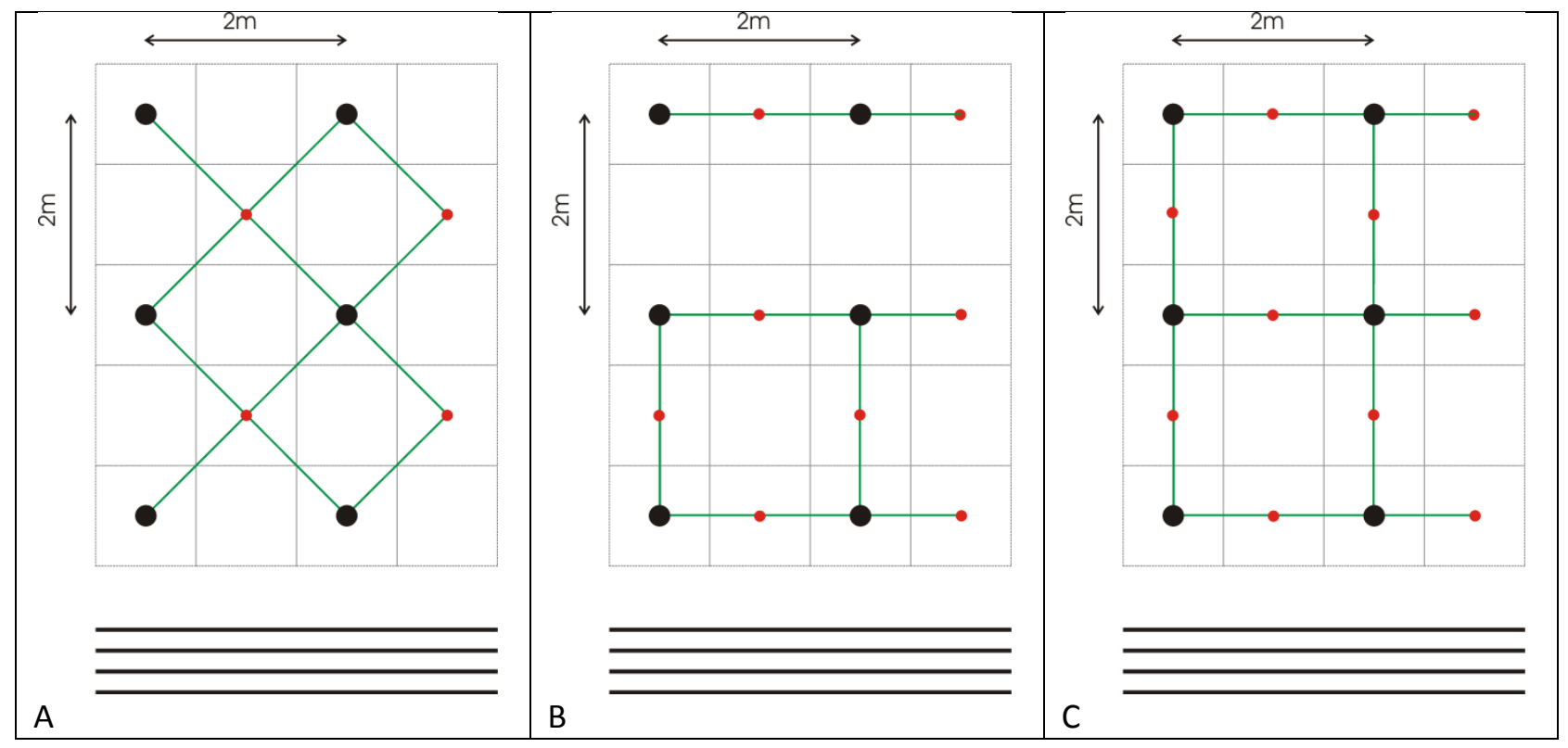




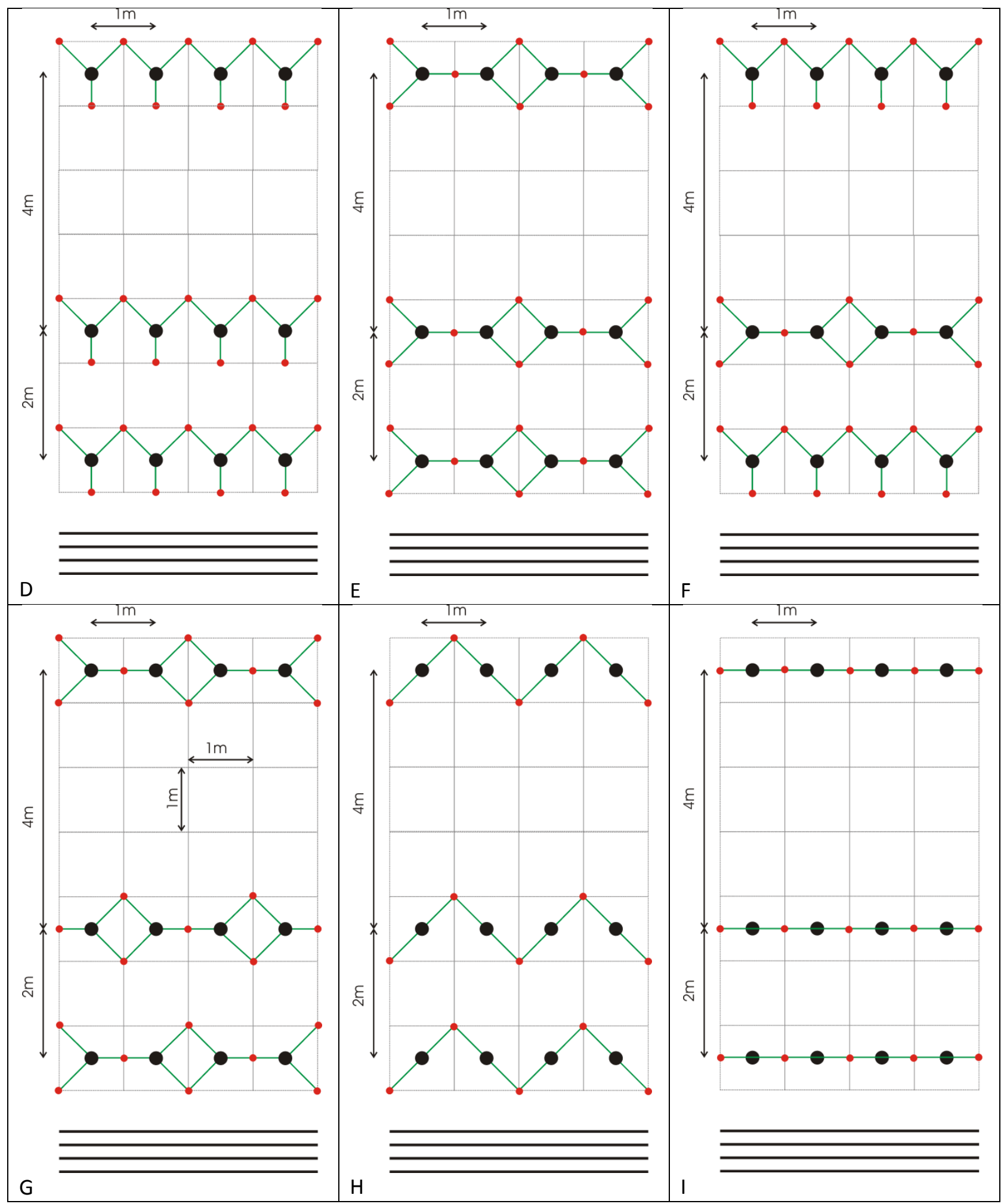

Figure 3. Plan view of (part of) the supporting pole setups applied to a regular square grid with a 2-m on 2-m spacing between trees $(A-C)$, and rectangular grids with a 1-m on 2-m spacing where each third row is omitted (D-I). The four thick black parallel lines indicate the positions of the traffic lanes, the black large dots the tree trunks and the red small dots the poles, the green lines show the attachments between the trunks and the nearest poles. 


\section{Numerical results}

All numerical results are depicted in Fig. 4 (see also Table 1 for the numerical values) in function of the tree trunk basal area, which was shown to be the basic parameter for predicting road traffic noise shielding as discussed in detail in Ref. [3]. The results obtained within the framework of the current work were added to the large number of calculations performed earlier [3] to allow comparison.

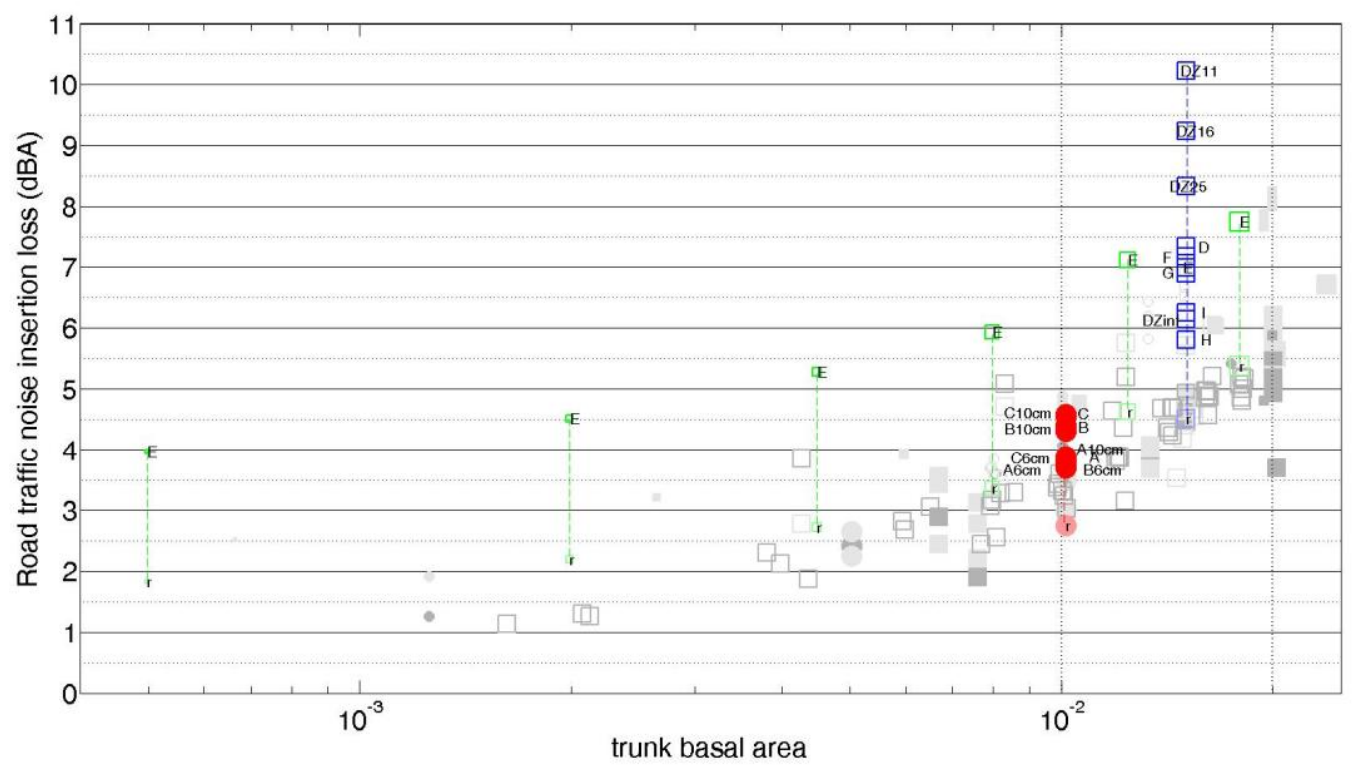

Figure 4. Scatter plot between tree trunk basal area and road traffic noise insertion loss (IL, relative to grassland) of a 15-m deep tree belt bordering a 4-lane road at a receiver behind the belt (receiver at $30 \mathrm{~m}$ relative to the interface between the tree belt and the road, at a receiver height of $1.5 \mathrm{~m}$ ). Simulations including supporting poles are plotted on top of the large number of simulations of planting schemes (grey symbols) described in detail in Ref. [3]. The configurations including supporting poles are indicated with a symbol and a naming, and connected to the corresponding reference cases (without poles, indicated by " $r$ "). If not explicated, pole diameters are $8 \mathrm{~cm}$ and their surfaces are modeled by a normalized real impedance of $Z=51$; "Xcm" and "ZXX" are used for other diameters and impedances, respectively. The names " $\mathrm{A}$ " to " $\mathrm{I}$ " refer to the pole configurations as depicted in Fig. 3. Following traffic parameters were used: $15 \%$ heavy vehicles, all driving at $70 \mathrm{~km} / \mathrm{h}$, equally distributed over the 4 lanes as shown in Fig. 2. 
Table 1. Overview of numerical results and parameters related to the simulations of tree belts with supporting poles and their reference situations. For the 1-m on 2-m tree trunk spacing, each third row has been omitted.

\begin{tabular}{|c|c|c|c|c|c|c|c|}
\hline $\begin{array}{l}\text { pole setup } \\
\text { code }\end{array}$ & $\begin{array}{l}\text { IL (dBA) tree } \\
\text { belt with poles }\end{array}$ & $\begin{array}{l}\text { IL (dBA) tree belt } \\
\text { without poles }\end{array}$ & $\begin{array}{l}\text { normalized pole } \\
\text { impedance }\end{array}$ & $\begin{array}{l}\text { pole diameter } \\
(\mathrm{cm})\end{array}$ & $\begin{array}{l}\text { trunk diameter } \\
\qquad(\mathrm{cm})\end{array}$ & trunk spacing & $\begin{array}{l}\text { Trunk Basal } \\
\text { Area }\end{array}$ \\
\hline D & 7.3 & 4.5 & 51 & 8 & 22 & $1 \mathrm{~m}$ on $2 \mathrm{~m}$ & 0.015 \\
\hline $\mathrm{E}$ & 7.0 & 4.5 & 51 & 8 & 22 & $1 \mathrm{~m}$ on $2 \mathrm{~m}$ & 0.015 \\
\hline $\mathrm{F}$ & 7.2 & 4.5 & 51 & 8 & 22 & $1 \mathrm{~m}$ on $2 \mathrm{~m}$ & 0.015 \\
\hline G & 6.9 & 4.5 & 51 & 8 & 22 & $1 \mathrm{~m}$ on $2 \mathrm{~m}$ & 0.015 \\
\hline $\mathrm{H}$ & 5.8 & 4.5 & 51 & 8 & 22 & $1 \mathrm{~m}$ on $2 \mathrm{~m}$ & 0.015 \\
\hline $\mathrm{I}$ & 6.3 & 4.5 & 51 & 8 & 22 & $1 \mathrm{~m}$ on $2 \mathrm{~m}$ & 0.015 \\
\hline DZinf & 6.1 & 4.5 & Inf & 8 & 22 & $1 \mathrm{~m}$ on $2 \mathrm{~m}$ & 0.015 \\
\hline DZ25 & 8.3 & 4.5 & 25 & 8 & 22 & $1 \mathrm{~m}$ on $2 \mathrm{~m}$ & 0.015 \\
\hline DZ16 & 9.2 & 4.5 & 16 & 8 & 22 & $1 \mathrm{~m}$ on $2 \mathrm{~m}$ & 0.015 \\
\hline DZ11 & 10.2 & 4.5 & 11 & 8 & 22 & $1 \mathrm{~m}$ on $2 \mathrm{~m}$ & 0.015 \\
\hline A6cm & 3.7 & 2.8 & 51 & 6 & 22 & $2 \mathrm{~m}$ on $2 \mathrm{~m}$ & 0.010 \\
\hline A & 3.9 & 2.8 & 51 & 8 & 22 & $2 \mathrm{~m}$ on $2 \mathrm{~m}$ & 0.010 \\
\hline $\mathrm{A} 10 \mathrm{~cm}$ & 3.9 & 2.8 & 51 & 10 & 22 & $2 \mathrm{~m}$ on $2 \mathrm{~m}$ & 0.010 \\
\hline $\mathrm{B} 6 \mathrm{~cm}$ & 3.8 & 2.8 & 51 & 6 & 22 & $2 \mathrm{~m}$ on $2 \mathrm{~m}$ & 0.010 \\
\hline B & 4.4 & 2.8 & 51 & 8 & 22 & $2 \mathrm{~m}$ on $2 \mathrm{~m}$ & 0.010 \\
\hline $\mathrm{B} 10 \mathrm{~cm}$ & 4.3 & 2.8 & 51 & 10 & 22 & $2 \mathrm{~m}$ on $2 \mathrm{~m}$ & 0.010 \\
\hline $\mathrm{C} 6 \mathrm{~cm}$ & 3.9 & 2.8 & 51 & 6 & 22 & $2 \mathrm{~m}$ on $2 \mathrm{~m}$ & 0.010 \\
\hline C & 4.5 & 2.8 & 51 & 8 & 22 & $2 \mathrm{~m}$ on $2 \mathrm{~m}$ & 0.010 \\
\hline $\mathrm{C} 10 \mathrm{~cm}$ & 4.6 & 2.8 & 51 & 10 & 22 & $2 \mathrm{~m}$ on $2 \mathrm{~m}$ & 0.010 \\
\hline $\mathrm{E}$ & 4.0 & 1.8 & 51 & 8 & 4 & $1 \mathrm{~m}$ on $2 \mathrm{~m}$ & 0.001 \\
\hline E & 4.5 & 2.2 & 51 & 8 & 8 & $1 \mathrm{~m}$ on $2 \mathrm{~m}$ & 0.002 \\
\hline E & 5.3 & 2.7 & 51 & 8 & 12 & $1 \mathrm{~m}$ on $2 \mathrm{~m}$ & 0.005 \\
\hline $\mathrm{E}$ & 5.9 & 3.4 & 51 & 8 & 16 & $1 \mathrm{~m}$ on $2 \mathrm{~m}$ & 0.008 \\
\hline $\mathrm{E}$ & 7.1 & 4.6 & 51 & 8 & 20 & $1 \mathrm{~m}$ on $2 \mathrm{~m}$ & 0.012 \\
\hline $\mathrm{E}$ & 7.7 & 5.4 & 51 & 8 & 24 & $1 \mathrm{~m}$ on $2 \mathrm{~m}$ & 0.018 \\
\hline
\end{tabular}

The poles and the tree trunks exercise a more or less additive effect, independent of the tree trunk diameters. This is illustrated by a series of simulations where the tree trunk diameters increase from 4 $\mathrm{cm}$ (e.g. juvenile trees) to $24 \mathrm{~cm}$ (mature trees). Pole configuration E is used (see Fig. 3) with all poles having a diameter of $8 \mathrm{~cm}$. The differences in insertion losses between the situation with and without poles are in the range 2.1 to $2.6 \mathrm{dBA}$. Especially in case of the small-diameter trunks, the presence of poles makes the tree belt a useful noise abatement solution already from the beginning (4.0 dBA at 4$\mathrm{cm}$ diameter trees, corresponding to a tree trunk basal area of only 0.0005). Note that in this analysis, the ground effect is assumed to be similar for both the juvenile and mature tree belt, which is clearly a simplification.

For the scenarios where the tree spacing is $2 \mathrm{~m}$, both orthogonal and parallel to the road, configuration $\mathrm{C}(4.5 \mathrm{dBA})$ is a better choice than configuration A ( $3.9 \mathrm{dBA})$. In both cases, each trunk is connected to the 4 nearest poles (all having a diameter of $8 \mathrm{~cm}$ ) but the number of poles used in configuration $C$ is about the double as in $A$. The additional rows of poles in configuration $C$, relative to $B$, only yield $0.1 \mathrm{dBA}$ additional road traffic noise insertion loss.

For these scenarios $(A-C)$, pole diameters were varied $(6 \mathrm{~cm}, 8 \mathrm{~cm}$ and $10 \mathrm{~cm})$. In scenario $A$, there is hardly any improvement by increasing the pole diameter $(3.7 \mathrm{dBA}$ for a diameter of $6 \mathrm{~cm}$ to $3.9 \mathrm{dBA}$ at $10 \mathrm{~cm}$ ). For configurations $B$ and $C$, the difference between diameters $6 \mathrm{~cm}$ and $8 \mathrm{~cm}$ amounts to 0.5 and $0.7 \mathrm{dBA}$, respectively; the difference between pole diameters $8 \mathrm{~cm}$ and $10 \mathrm{~cm}$ stays very small (less than $0.1 \mathrm{dBA})$.

For the rectangular tree belt with the 1-m on 2-m spacing, and where each third row has been omitted to reduce the average tree trunk basal area, the acoustical efficiency increases with the number of poles per tree (for a fixed diameter and the current pole's absorption properties). Configurations D, E, F and G use 3 poles per tree, while configurations $\mathrm{H}$ and I only use two poles. Within each group the number of poles is more or less the same. There are some small differences in shielding, ranging from $0.4 \mathrm{dBA}$ in the series $\mathrm{D}-\mathrm{G}$, and $0.5 \mathrm{dBA}$ between $\mathrm{H}$ and $\mathrm{I}$. The fact that configuration $\mathrm{I}$ is slightly better than $\mathrm{H}$ is 
consistent with the idea of rectangular planting schemes [3], where a dense spacing along the road length axis is preferred, while orthogonal to the road the spacing could be larger. However, the preference for configurations $D$ and $\mathrm{I}$ is not very pronounced. Shifting the pole grid over $1 \mathrm{~m}$ for each second row, as is done in case $G$ relative to case $E$, hardly influences the predicted road traffic noise shielding $(<0.1 \mathrm{dBA})$.

Making the supporting poles more absorbing gives a large improvement in the road traffic noise insertion loss. In the basic scenario, a similar impedance as used for the tree trunks $(Z=51)$ is imposed on the outer surface of the cylinders representing the supporting poles. Fully rigid poles ( $Z=$ infinity) give a more modest shielding than $Z=51$ (1.2 dBA lower), while with decreasing impedance the insertion loss increases (additional calculations were performed for $Z=25, Z=16$ and $Z=11$ ). For $Z=11$, the predicted insertion loss exceeds $10 \mathrm{dBA}$. In comparison, the same case without poles yields $4.5 \mathrm{dBA}$. On condition that absorption can be applied, here modeled as a simplified frequency-independent behavior without having a specific material in mind, absorbing poles could strongly add to road traffic noise shielding of a non-deep tree belt.

Making a second grid of cylindrical scatterers, which is actually done by adding poles to the tree belts in a structured way, shows to be efficient. The insertion losses predicted for tree belts with poles are larger than the insertion loss one would expect for trunks alone with the same wood basal area (so tree trunk basal area and pole basal area summed together). This effect is especially pronounced in case of thin trees. Similar to the findings for tree belts without supporting poles, the trunk basal area only provides a first estimate and significant improvements relative to this basic behavior are possible.

When the reference case is sound propagation over rigid ground (instead of grassland outside the road as in all previously cited predictions), the insertion losses for the cases considered in Fig. 3 are on average $6.6 \mathrm{dBA}$ larger (with a standard deviation of $0.2 \mathrm{dBA}$ ). For a $15-\mathrm{m}$ deep belt with tree and pole configuration $\mathrm{D}$, the insertion loss then amounts up to $13.7 \mathrm{dBA}$ (which was $7.3 \mathrm{dBA}$ in case of grassland in the reference case).

The results presented in this work are based on numerical simulations, inevitably involving some idealizations. However, arguments are given in this paragraph allowing reasonable confidence in the results obtained. Firstly, detailed sound propagation models were used; scattering of sound by cylinders (tree trunks) can be accurately predicted by a full-wave method like FDTD, while GFPE accurately describes ground effects and associated impedance jumps. Acoustical parameters used to describe the forest floor effect [20] and tree bark absorption [21] are based on sets of measurements. Justification for the reduction to two orthogonal propagation planes is given in Section 2. In addition, road traffic source modelling has been an important research topic since long, leading to continued improvements [19]. However, true validation of sound reduction by optimized tree belts is not available given the major practical issues involved: only sufficiently extended tree belts reduce road traffic noise, while trees take decades to develop. To some extent, a comparison is possible with measurements by Tanaka et al. [22]. For trunk basal areas up to 0.07 , insertion losses ranged from $0 \mathrm{~dB}$ to $4 \mathrm{~dB}$ (only integer values are given in [22]; propagation distances were between $10 \mathrm{~m}$ and $20 \mathrm{~m}$, relative to a forest edge). This corresponds to the predicted range in Fig. 4 at low trunk basal areas. 


\section{Conclusions}

Supporting poles can be exploited to increase the road traffic noise insertion loss of both juvenile and mature tree belts. The presence of wooden poles could make a juvenile tree belt a viable noise abatement solution. Numerical predictions showed that specific configurations of supporting poles should be considered in order to optimize the noise shielding. Adding absorption, here modeled in a simplified approach, strongly increases the road traffic noise abatement although the total amount of the pole's outer surfaces is actually limited. 


\section{References}

[1] M. Nilsson, J. Bengtsson, R. Klaeboe (Eds.): Environmental methods for transport noise reduction. CRC Press, Taylor \& Francis Group, Boca Raton, US, 2015.

[2] T. Van Renterghem, D. Botteldooren, K. Verheyen: Road traffic noise shielding by vegetation belts of limited depth. Journal of Sound and Vibration 331 (2012) 2404-2425.

[3] T. Van Renterghem: Guidelines for optimizing road traffic noise shielding by non-deep tree belts. Ecological Engineering 69 (2014) 276-286.

[4] R. Lyon: Evaluating effects of vegetation on the acoustical environment by physical scale-modeling. In: Proceedings of the Conference on Metropolitan Physical Environment, USDA Forest Service General Technical Report NE-2, 1977.

[5] H. Yang, J. Kang, C. Cheal, T. Van Renterghem, D. Botteldooren: Quantifying scattered sound energy from a single tree by means of reverberation time. Journal of the Acoustical Society of America 134 (2013) 264-274.

[6] T. Van Renterghem, D. Botteldooren: Effect of a row of trees behind noise barriers in wind. Acta Acustica united with Acustica 88 (2002) 869-878.

[7] M. Martens: Foliage as a low-pass filter - experiments with model forests in an anechoic chamber. Journal of the Acoustical Society of America 67 (1980) 66-72.

[8] J. Kragh: Road traffic noise attenuation by belts of trees. Journal of Sound and Vibration 74 (1981) 235-241.

[9] W. Huisman, K. Attenborough: Reverberation and attenuation in a pine forest. Journal of the Acoustical Society of America 90 (1991) 2664-2677.

[10]H. Jonasson: Sound reduction by barriers on the ground. Journal of Sound and Vibration 22 (1972) 113-126.

[11]ISO 9613-2:1996. Acoustics - attenuation of sound during propagation outdoors - Part 2. International Organisation for Standardisation, Geneva, Switzerland; 1996.

[12]D. Botteldooren: Acoustical finite-difference time-domain simulation in a quasi-Cartesian grid. Journal of the Acoustical Society of America 95 (1994) 2313-2319.

[13]K. Gilbert, X. Di: A fast Green's function method for one-way sound propagation in the atmosphere. Journal of the Acoustical Society of America 94 (1993) 2343-2352.

[14]E. Salomons: Improved Green's function parabolic equation method for atmospheric sound propagation. Journal of the Acoustical Society of America 104 (1998) 100-111.

[15]D. Aylor: Noise reduction by vegetation and ground. Journal of the Acoustical Society of America 51 (1972) 197-205.

[16]M. Price, K. Attenborough, N. Heap: Sound-attenuation through trees - measurements and models. Journal of the Acoustical Society of America 84 (1988) 1836-1844.

[17]B. van der Aa, J. Forssén: The 2.5D MST for sound propagation through an array of acoustically rigid cylinders perpendicular to an impedance surface. Journal of Physics D: Applied Physics 48 (2015) 295501.

[18]T. Van Renterghem, E. Salomons, D. Botteldooren: Efficient FDTD-PE model for sound propagation in situations with complex obstacles and wind profiles. Acta Acustica united with Acustica 91 (2005) 671-679.

[19]H. Jonasson: Acoustical source modelling of road vehicles. Acta Acustica united with Acustica 93 (2007) 173-184.

[20]K. Attenborough, I. Bashir, S. Taherzadeh: Outdoor ground impedance models. Journal of the Acoustical Society of America 129 (2011) 2806-2819. 
[21]G. Reethof, L. Frank, O. McDaniel: Sound absorption characteristics of tree bark and forest floor. In: Proceedings of the Conference on Metropolitan Physical Environment, USDA Forest Service General Technical Report NE-2, 1977.

[22]K. Tanaka, S. Ikeda, R. Kimura, K. Simazawa: The function of forests in sound-proofing. Research Bulletin of the Tottori University Forests 11 (1979) 77-102. 